\title{
Evaluation of levels of vitamin D in immigrant and refugee children: single center experience
}

\begin{abstract}
Background: Immigrant and refugee populations are prone to important public health problems and among them and children constitute the most vulnerable subpopulation. The aim of this study is to evaluate the vitamin D levels of immigrant and refugee children.
\end{abstract}

\begin{abstract}
Methods: In the study, 4612 immigrant and refugee patients aged between 0 and 18years, in the years 2012-2018, were evaluated, retrospectively. The patients whose vitamin $250 \mathrm{HD}$ levels were coded included in the study. The patients were evaluated in terms of their age, nationality, gender, vitamin D levels and blood collection time, as well as calcium and phosphorus levels.
\end{abstract}

Results: A total of 279 cases, whose vitamin D levels were examined, included in the study. Out of the cases, 149 were female $(53.4 \%)$ and 275 were Syrians. Median age value was found to be three months (0-18). According to the vitamin D levels; vitamin D deficiency $(<20 \mathrm{ng} / \mathrm{ml})$, vitamin D insufficiency $(20-30 \mathrm{ng} / \mathrm{ml})$, and vitamin D sufficiency $(>30 \mathrm{ng} / \mathrm{ml})$ were found to be $68.1 \%, 19.7 \%$ and $12.2 \%$, respectively. Vitamin D levels were observed to be lower on sunless days $(\mathrm{p}=0.049)$. Age average of those who suffered from vitamin $\mathrm{D}$ deficiency was significantly higher $(\mathrm{p}=0.04)$. It was determined that calcium levels were higher in the group with numerically higher vitamin D levels; however, they were not statistically significant.

Conclusion: Vitamin D deficiency is a preventable public health problem. We should consider administering the vitamin D prophylaxis in immigrant and refugee children.

Keywords: vitamin D, child, immigrant, refugee, prophylaxis, syrians, cardiomyopathy, hypocalcemic seizures, growth retardation, muscle weakness, rickets
Volume 8 Issue 5 - 2019

\author{
Dilek Orbatu, Demet Alaygut, Oya Baltali \\ Department of Pediatrics, Tepecik Training and Research \\ Hospital,Turkey
}

\section{Correspondence: Dilek Orbatu, Department of Pediatrics, Tepecik Training and Research Hospital,Turkey, Tel} 905057556579, Email drdilekorbatu@gmail.com

Received: October 12, 2019| Published: October 17, 2019
Abbreviations: PTH, parathyroid hormone; ALP, alkaline phosphatase; IU, Internationalunit; HD, hemodialysis; $\mathrm{OH}$, alcohol

\section{Introduction}

Immigrant and refugee populations are prone to important public health problems and among them, children constitute the most vulnerable subpopulation. In infancy, a sufficient level of vitamin $\mathrm{D}$ is important for a healthy development and childhood. ${ }^{1}$ Vitamin D support is necessary because the infant's needs are insufficient in breast milk especially within the first 6 months of breastfeeding. ${ }^{2}$ Since 2012-2015 when the global refugee crisis started, especially Turkey and other high-income countries have faced yearly considerable immigrant and refugee populations and various health problems. ${ }^{3}$ National health planners need to estimate medical consequences to be caused by the increasing immigrant and refugee influx and make preparations. ${ }^{4}$ Health problems such as diseases with increasing prevalence and nutritional insufficiencies should be included in that planning. ${ }^{5}$ Vitamin D deficiency is an important health problem in childhood. ${ }^{5}$

It is frequently prevalent in countries such as Middle East, North Africa, Yemen, Qatar, Saudi Arabia and Turkey due to covering, ${ }^{6}$ for many populations, the basic source of vitamin D is the ultraviolet effect in sunlight and its production by skin. Some foods are rich in vitamin D. ${ }^{3}$ In case of exposure to insufficient sunlight, children should be given foods strengthened with vitamin $\mathrm{D}$ or vitamin $\mathrm{D}$ support. ${ }^{3}$ In addition, immigrant and refugee children face some problems such as being unable to consume foods that are rich in vitamin D or get foods that are rich in vitamin $\mathrm{D}$ during immigration in daily intake depending on their dietary habits. ${ }^{7}$ Vitamin D deficiency may have significant consequences such as delayed motor development, growth retardation, muscle weakness, rickets characterized by insufficient bone mineralization, hypocalcemic seizures, cardiomyopathy, and sudden deaths. ${ }^{8}$ In order to determine this preventable public health problem among the immigrant and refugee population, it was aimed to evaluate the vitamin D levels in children in this group.

\section{Methods}

In the study, 4612 immigrant and refugee patients aged between 0 and 18, who applied to the Pediatric Clinics of T.C Ministry of Health Izmir University of Health Sciences Tepecik Training and Research Hospital including the years of 2012-2018, were evaluated retrospectively. Izmir is located in the west of Turkey and is a developed city and host more immigrants. The hospital is a tertiary hospital and provides free services to immigrants. 279 patients who admitted to the hospital for any reason and whose vitamin $25(\mathrm{OH}) \mathrm{D}_{3}$ levels were coded were reached and included in the study.

It was planned to evaluate these patients in terms of their age, nationality, gender, vitamin D levels and blood-letting times for vitamin D, as well as calcium, phosphorus, ALP and PTH levels that were measured concurrently. All the patients aged between 0 and 18 who had vitamin D levels were included in the study. Those with chronic disease and malignancy were not included in the study. 
Three patient groups were formed according to their vitamin D levels. Vitamin D deficiency was defined as having vitamin D level below $<20 \mathrm{ng} / \mathrm{ml}$ (Group 1); vitamin D insufficiency was defined as having vitamin D level below (20-30ng/ml) (Group 2); and vitamin D sufficiency was defined as having vitamin D level above $(>30 \mathrm{ng} / \mathrm{ml})$ (Group 3). On the other hand, the month range of blood sampling for vitamin D levels was defined in two periods as May-September (sunny days) and October-April (sunless days). The data were transferred to the SPSS 24.0 software and while descriptive statistical methods and categorical data were compared using chi-square, numeric data were compared using student t-test.

\section{Results}

279 cases whose vitamin D levels were examined from 20122018 were included in the study. Among the cases, 149 were female (53.4\%). Median age value (SD, Range) was found to be three months (0-18). 275 of the cases were Syrian (98.6\%). According to the vitamin D levels; vitamin D deficiency $(<20 \mathrm{ng} / \mathrm{ml})$, vitamin D insufficiency $(20-30 \mathrm{ng} / \mathrm{ml})$ and vitamin D sufficiency $(>30 \mathrm{ng} / \mathrm{ml})$ were found to be $68.1 \%, 19.7 \%$ and $12.2 \%$, respectively. Mean vitamin D level of a total of 279 cases was found to be $14.2 \mathrm{ng} / \mathrm{ml}$. The blood sampling times of the cases whose vitamin D levels were measured were separated into two as May-September (sunny days) and October-April (sunless days). Vitamin D levels were observed to be significantly lower on the sunless days (October-April) $(\mathrm{n}=150,21.3 \%, \mathrm{p}<0.05)$. The patients whose vitamin D levels were examined were also evaluated in terms of their age, calcium and phosphorus levels. Age average of the patients who suffered from vitamin D deficiency was significantly higher $(p<0.04)$. It was determined that calcium levels were higher in the group with numerically higher vitamin D levels; however, they were not statistically significant ( $\mathrm{p}>0.005)$.

\section{Discussion}

Causing clinical pathologies with a high potential morbidity and mortality which could be prevented with supportive treatments, vitamin D deficiency was evaluated in our region where immigrant and refugee populations are intense. According to Munns et al., ${ }^{5}$ the studies that are conducted in immigrant-receiving sections of countries where immigrant and refugee influx is intense and there are distinct changes in child population have shown increasing rates of vitamin $\mathrm{D}$ deficiency findings and the presence of associated clinical pathologies. ${ }^{3}$ In a study, it was found that nutritional vitamin D deficiency gradually increased in regions where people were ethnically darker or wore traditionally covered clothes, had a lower calcium intake in their diet and were immigrants and refugees. ${ }^{9}$ This difference was more evident in high-income countries.

According to Goldacre M. et al., ${ }^{10}$ the pathologies (rickets, hypocalcemic seizures) depending on vitamin D deficiency findings, as the cause of hospitalization in England for the past 50 years from 1963 to 2011, are more prevalent in regions where immigrant and refugee populations are intense and due to all these reasons, the hospitalization durations extend. ${ }^{10}$ In a study conducted by Basatemur E. et al., ${ }^{11}$ vitamin D deficiency may also cause rickets and various bone deformities in adolescents and osteomalacia which becomes more difficult to diagnose and treat in adulthood may bring along more severe complications such as muscle weakness. ${ }^{11}$ In the present study, vitamin D deficiency was found to be $68.1 \%$ in patients whose vitamin D levels were coded without knowing their symptoms and clinical complaints, which shows a parallelism with the literature.
Median value of vitamin D was also lower. Because blood-sampling time for vitamin D level is also important in these cases, we evaluated the time in the present study, as well. Vitamin D levels were observed to be significantly lower on sunless days (October-April) (Table 1).

Table I Vitamin D levels and Blood sampling times of patients

\begin{tabular}{lll}
\hline Parameter & Number & P \\
\hline Vitamin D levels & & \\
Group I & $190(\% 68.1)$ & \\
Group 2 & $55(\% \mid 9.7)$ & \\
Group 3 & $34(\% \mid 2.2)$ & \\
Blood sampling times & & \\
May-September & & 0.049 \\
October- April & $129(\% \mid 6.7)$ & \\
& $150(\% 21.3)$ & \\
\hline
\end{tabular}

It is possible to reach different studies in the literature concerning the seasonal vitamin D results. In the study by Behzat $\mathrm{O}$. et al., ${ }^{19} \mathrm{Ca}, \mathrm{P}$ and vitamin $25(\mathrm{OH}) \mathrm{D}$ levels that were examined in the age group of 0-3 years were found to be low; however, considering in terms of bloodsampling time, vitamin D deficiency and association with clinical pathologies were not found to be seasonally significant. ${ }^{12}$ In the study by Halicioglu et al., ${ }^{13}$ on the other hand; it was determined that vitamin D level was sufficient only in 48 (33.6\%) of 143 infants receiving breast milk and daily $400 \mathrm{IU}$ vitamin D and calcium, phosphorus and vitamin D levels were significantly lower on sunless days. ${ }^{13}$ Grant $\mathrm{CC}$ et al., ${ }^{14}$ found that seasonal vitamin D insufficiency was distinct in 6-23month-old children who had different dietary habits. ${ }^{14}$ On the contrary, two studies conducted in Israel and India showed that there was no dependence on seasonal differences in children from different age groups. ${ }^{15,16}$ In a study which was conducted with the voluntary participation of 8024 Romanians (median age 50 and $17.8 \%$ male); it was determined that vitamin D levels were the highest in September and the lowest in March. No gender difference was specified. ${ }^{17}$ In another study investigating seasonal vitamin $\mathrm{D}$ levels in children with asthmatic and allergic rhinitis, it was found that vitamin D levels were the highest in summer and the lowest in winter. ${ }^{18}$ Also, in the present study, vitamin D levels were found to be lower in blood samples taken between October-April defined on sunless days (Table 2).

Table 2 Ages, calcium and phosphor levels of patients

\begin{tabular}{llll}
\hline & Group I & Group 2 & $\mathbf{P}$ \\
\hline Ages & $\mathrm{n}=190$ & $\mathrm{n}=89$ & 0,004 \\
& $5,21 \pm 4,75$ & $3,57 \pm 3,39$ & \\
Phosphorus & $\mathrm{n}=40$ & $\mathrm{n}=31$ & 0,591 \\
& $5,18 \pm 1,19$ & $5,32 \pm 1,07$ & \\
Calcium & $\mathrm{n}=55$ & $\mathrm{n}=41$ & 0,059 \\
& $9,71 \pm 0,86$ & $10,02 \pm 0,7$ & \\
\hline
\end{tabular}

In the study by Doneray H. et al., ${ }^{12}$ they determined that the rate of cases with rickets between the ages of 0 and 3 in Erzurum in 1998 was $6 \%$ and this was a common problem related with insufficient vitamin $\mathrm{D}$ intake and especially children and adolescents were in the risk group. Also in the present study; age average of those with vitamin D deficiency was significantly higher. ${ }^{19}$ Mutlu et al. ${ }^{20}$ determined vitamin D deficiency and insufficiency in $12 \%$ of children aged between $3-18$ 
months receiving $400 \mathrm{IU}$ vitamin D support in spring or summer, ${ }^{20}$ in this study, age average of those with vitamin D deficiency was significantly higher. Cases not receiving vitamin D support will suffer from vitamin D deficiency or insufficiency in advanced age as well, ${ }^{15}$ in the study, higher vitamin D levels in children having higher average age were associated with children's inability of continuing the vitamin $\mathrm{D}$ support or getting diet and vitamin D support during immigration.

The patients who could be reached were evaluated in terms of their vitamin D levels, as well as calcium and phosphorus levels that were measured concurrently. In parallel with the literature, the present study has revealed that calcium levels were higher in the group with higher vitamin D levels; however, they were not statistically significant. On the other hand, PTH level increased with the decrease of vitamin D level.

In the present study, PTH and ALP levels could not be found in patient records. Additionally, data such as maternal $25(\mathrm{OH}) \mathrm{D}$, ALP and PTH could not be reached, which is one of limitations of the study. As a consequence, this study evaluated vitamin D levels of immigrant and refugee children, who constitute a population that is prone to important health problems. Due to reasons such as absence of regular vitamin D supplementation, diet with poor calcium and insufficient use of sunlight in the immigrant and refugee population; vitamin D levels were found to be lower in the populations evaluated, as expected. Vitamin D deficiency is a preventable public health problem. It is required to apply the daily 400 IU vitamin D supplementation treatment, which was started by the T.R. Ministry of Health across the nation for free in 2005 , in this population within the first year of national life as well. Clinicians should be more careful and interrogative towards patients who apply to the health center concerning this issue.

\section{Acknowledgments}

None

\section{Conflicts of interest}

The author declares that there are no conflicts of interest.

\section{Funding}

No

\section{References}

1. Madar AA, Stene LC, Meyer HE. Vitamin D status among immigrant mothers from Pakistan, Turkey and Somalia and their infants attending child health clinics in Norway. Br J Nutr. 2009;101(7):1052-1058.

2. Madar AA, Gundersen TE, Haug AM. Vitamin D supplementation and vitamin D status in children of immigrant background in Norway. Public Health Nutr. 2017;20(16):2887-2892.

3. Thacher TD, Pludowski P, Shaw NJ, et al. Nutritional rickets in immigrant and refugee children. Public Health Rev. 2016;37:3.
4. Weise Prinzo Z, de Benoist B. Meeting the challenges of micronutrient deficiencies in emergency-affected populations. Proc Nutr Soc. 2002;61(2):251-257.

5. Munns CF, Shaw N, Kiely M, et al. Global consensus recommendations on prevention and management of nutritional rickets. J Clin Endocrinol Metab. 2016;101(2):394-415.

6. Munns CF, Simm PJ, Rodda CP, et al. Incidence of vitamin D deficiency rickets among Australian children: an Australian Paediatric Surveillance Unit study. Med J Aust. 2012;196(7):466-468.

7. Modgil G, Williams B, Oakley G, et al. High prevalence of Somali population in children presenting with vitamin D deficiency in the UK. Arch Dis Child. 2010;95:568-569.

8. Ward LM, Gaboury I, Ladhani M, et al. Vitamin D-deficiency rickets among children in Canada. CMAJ. 2007;177(2):161-166.

9. Ashraf S, Mughal MZ. The prevalence of rickets among non-Caucasian children. Arch Dis Child. 2002;87(3):263-264.

10. Goldacre M, Hall N, Yeates DG. Hospitalisation for children with rickets in England: a historical perspective. Lancet. 2014;383(9917):597-598.

11. Basatemur E, Sutcliffe A. Incidence of hypocalcemic seizures due to vitamin D deficiency in children in the United Kingdom and Ireland. $J$ Clin Endocrinol Metab. 2015;100(1):E91-95.

12. Ozkan B, Doneray H, Karacan M, et al. Prevalence of vitamin D deficiency rickets in the eastern part of Turkey. Eur J Pediatr. 2009;168(1):95-100.

13. Halicioglu O, Sutcuoglu S, Koc F, et al. Vitamin D status of exclusively breastfed 4-month-old infants supplemented during different seasons. Pediatrics. 2012;130(4):e921-927.

14. Grant CC, Wall CR, Crengle S, et al. Vitamin D deficiency in early childhood: prevalent in the sunny South Pacific. Public Health Nutr. 2009;12(10):1893-1901.

15. Oren Y, Shapira Y, Agmon-Levin N, et al. Vitamin D insufficiency in a sunny environment: a demographic and seasonal analysis. Med Assoc $J$ Isr. 2010;12(12):751-756.

16. Jain V, Gupta N, Kalaivani M, et al. Vitamin D deficiency in healthy breastfed term infants at 3 months \& their mothers in India: seasonal variation \& determinants. Indian J Med Res. 2011;133(3):267-273.

17. Niculescu DA, Capatina CAM, Dusceac R, et al. Seasonal variation of serum vitamin D levels in Romania. Arch Osteoporos Dec. 11;12(1):113.

18. Sopo SM, Cerchiara G, Bersani G, et al. The unpredictability of seasonal variations in serum vitamin $\mathrm{D}$ levels in children with asthma and/or rhinitis. Allergol Immunopathol (Madr). 2019;47(5):411-416.

19. Hakan Döneray, Behzat Özkan, Asuman Özkan, et al. The Clinical and Laboratory Characteristics of Vitamin D Intoxication in Children. Turk $J$ Med Sci. 2009;39(1):1-4

20. Mutlu GY, Kusdal Y, Ozsu E, et al. Prevention of Vitamin D deficiency in infancy: daily $400 \mathrm{IU}$ vitamin D is sufficient. Int J Pediatr Endocrinol. 2011;2011(1):4 